\title{
Cytolethal distending toxin as virulence factor, protective antigen, and target for vaccine development
}

This article was published in the following Dove Press journal:

Vaccine: Development and Therapy

5 December 2012

Number of times this article has been viewed

\section{Teresa Lagergård' \\ Jerry Keith ${ }^{2}$}

'Institute of Biomedicine, Department of Microbiology and Immunology, Sahlgrenska Academy, University of Gothenburg, Göteborg, Sweden; ${ }^{2}$ Eunice Kennedy Shriver National Institute of Child Health and Human Development (NICHD), NIH, Bethesda, MD, USA
Correspondence:Teresa Lagergård Medicinaregatan 7A, Box 435, Institute of Medicine, Department of Microbiology and Immunology, Sahlgrenska Academy, University fg Gothenburg,

40530 Göteborg, Sweden

$\mathrm{Tel}+46317866220$

Fax +46 3I 7866210

Email teresa.lagergard@microbio.gu.se
Abstract: This review explores the cytolethal distending toxin (CDT) as a virulence factor, protective antigen, and a vaccine candidate in diseases caused by the following bacterial pathogens: Haemophilus ducreyi (HdCDT), Aggregatibacter actinomycetemcomitans, Campylobacter jejuni, and Helicobacter hepaticus. The review highlights some of the important evidence indicating that CDT is not only a commonly invoked virulence factor involved in pathogenesis of infection caused by these bacteria, but is also a protective antigen, such that specific antibodies will neutralize cell damage caused by the toxin. This justifies the development of toxoids as vaccine candidates. The first immunogenic toxoid was produced by formaldehyde treatment of HdCDT and has been used to study the involvement of antibodies in protection against infection and its use as a future vaccine component. The development of such toxoid vaccines may facilitate the studies of protection and immunoprophylaxis in diseases caused by CDT-producing bacteria.

Keywords: cytolethal distending toxin, virulence factor, protective antigen, Haemophilus ducreyi, Aggregatibacter actinomycetemcomitans, Campylobacter jejuni, toxoid vaccine

\section{Introduction}

Cytolethal distending toxin (CDT) is a trimeric subunit toxin produced by some Gram-negative bacterial human mucosal pathogens. The most important are Haemophilus ducreyi, Aggregatibacter actinomycetemcomitans, Campylobacter spp., Helicobacter spp., some Escherichia coli strains and some Shigella spp. ${ }^{1-3}$ This review explores the CDT of the following bacterial pathogens: H. ducreyi (HdCDT), A. actinomycetemcomitans (AaCDT), Campylobacter jejuni (CjCDT) and Helicobacter hepaticus (HhCDT) (Table 1). The high prevalence of the CDT genes and their association with toxic activity in clinical strains suggests a possible critical role for the toxin in the pathogenesis of the diseases caused by these pathogens.

$H$. ducreyi is the etiological agent of chancroid, a human sexually transmitted infection (STI), characterized by localized development of persisting ulcers on the mucosa or skin of mainly the external genitals. ${ }^{4,5}$ The first sign of infection is a small papule at the site of contact with bacteria, which becomes pustular and finally ulcerates. The ulcer enlarges, and ragged, defined, sharply marked borders, surrounded by erythema develop. HdCDT is produced by a majority $(>80 \%)$ of $H$. ducreyi patient strain isolates. ${ }^{6-8}$

A. actinomycetemcomitans is involved in the development of periodontitis, in which significantly elevated levels of bacteria can be detected in lesions. The infection is 
Table I CDT-producing bacteria, prevalence, their hosts, associated disease, localization of infection, and production of other toxins

\begin{tabular}{|c|c|c|c|c|}
\hline $\begin{array}{l}\text { Genus and species } \\
\text { (prevalence of CDT } \\
\text { genes/toxic activity) }\end{array}$ & Host & Disease & Localization & Other toxins \\
\hline $\begin{array}{l}\text { Haemophilus ducreyi } \\
(>80 \%)\end{array}$ & Human & $\begin{array}{l}\text { Sexually transmitted persisting genital } \\
\text { ulcer (chancroid, soft chancre) }\end{array}$ & $\begin{array}{l}\text { Genital tract, mostly } \\
\text { external genitals }\end{array}$ & $\begin{array}{l}\text { Hemolysin } \\
\text { (cell-associated) }\end{array}$ \\
\hline $\begin{array}{l}\text { Aggregatibacter } \\
\text { actinomycetemcomitans } \\
(>80 \%)\end{array}$ & Human & $\begin{array}{l}\text { Localized aggressive periodontitis, } \\
\text { gingival sulcus, dental plaque, } \\
\text { commensal }\end{array}$ & Oral cavity & $\begin{array}{l}\text { Leukotoxin } \\
\text { kills PMN and } \\
\text { monocytes }\end{array}$ \\
\hline $\begin{array}{l}\text { Campylobacter jejuni } \\
(>95 \%)\end{array}$ & $\begin{array}{l}\text { Human, nonhuman primates, } \\
\text { cattle, ship, pig, dog, chicken }\end{array}$ & $\begin{array}{l}\text { Acute gastroenteritis, often } \\
\text { self-limiting, enterocolitis and } \\
\text { commensal in animals }\end{array}$ & $\begin{array}{l}\text { Intestinal mucosa in the } \\
\text { jejunum, the ileum, and } \\
\text { the colon }\end{array}$ & Not known \\
\hline $\begin{array}{l}\text { Helicobacter hepaticus } \\
\text { (not known) }\end{array}$ & Mice, mammals, and humans & $\begin{array}{l}\text { Chronic inflammatory disease } \\
\text { of intestine, enterocolitis/hepatitis }\end{array}$ & $\begin{array}{l}\text { Intestinal mucosa, biliary } \\
\text { tract }\end{array}$ & Not known \\
\hline
\end{tabular}

Abbreviations: CDT, cytolethal distending toxin; PMN, polymorphonuclear leukocytes.

located in the oral cavity and results in an inflammatory, often chronic disease affecting mucosa and tissue that surrounds and supports teeth. CDT genes and toxic activity have been detected in $86 \%-95 \%$ of $A$. actinomycetemcomitans patient strain isolates. ${ }^{8-12}$

C. jejuni is the most prevalent bacterial food-borne pathogen in the industrial world to date. ${ }^{13}$ The bacterium is a zoonotic pathogen with widespread occurrence in the environment and in various animals. It can also establish a long-term, asymptomatic association with many hosts. For example, chickens are natural hosts for $C$. jejuni and colonized broiler chicks are the primary vector for transmitting this pathogen to humans. ${ }^{14} \mathrm{CDT}$ is the only verified toxin produced by $C$. jejuni and the prevalence of toxin-producing strains is high. ${ }^{15}$ Polymerase chain reaction (PCR) typing showed that the prevalence of all three $C$. jejuni CDT genes in strains originating from human, cattle, sheep, dog, and poultry was $87 \%, 67 \%, 84 \%, 89 \%$, and $39 \%$, respectively. ${ }^{16}$ Another study using multiple PCR demonstrated expression of the three CDT genes in $98 \%$ of human and animal isolates from different geographic origins. ${ }^{17}$ Closely related to $C$. jejuni, H. hepaticus, the enterohepatic Helicobacter species is a murine pathogen, which colonizes the lower intestinal and hepatobiliary tracts of mice and causes colitis, hepatitis, and hepatocellular carcinoma. HhCDT is the only known virulence factor found in $H$. hepaticus. ${ }^{18-21}$

Bacterial CDT is a group of heterodimeric toxins, which block the cell cycle of a broad range of mammalian cells. The mode of action is well documented by many studies and the subject has been reviewed extensively. ${ }^{1,211,22}$

CDT of these bacteria is located in the bacterial periplasmic space, and in culture supernatants, indicating active secretion from bacterial cells. For HdCDT and AaCDT, it has been suggested that a complex is formed inside the periplasm, and that post-translational processing of CdtA plays an important role for the efficient secretion of CDT holotoxin into the culture supernatant. ${ }^{23-25}$ For C. jejuni, Lindmark et al observed that the release of outer membrane vesicles function as delivery vehicles for all the subunits of CjCDT to the surrounding environment, including infected host tissue. ${ }^{26} \mathrm{In}$ the pathogenesis of $C$. jejuni infection, outer membrane vesicles may protect CDT against enzymatic digestion, thus enhancing the local activity of the toxin on the gut mucosa.

CDT blocks cell proliferation of cultured epithelial and endothelial cells at $\mathrm{G} 2$ and of fibroblasts at $\mathrm{G} 1 / \mathrm{S}$ and G2/M. In some cells, cycle arrest leads to enlargement or distention of cells (hence the name of the toxin) followed by cellular death. 1,2,27-29

CDT toxins comprise three proteins, $\mathrm{CdtA}, \mathrm{CdtB}$, and $\mathrm{CdtC}$, encoded by three linked, chromosomal genes $c d t A B C$. The molecular masses of the individual CdtA, CdtB, and $\mathrm{CdtC}$ proteins are approximately $24 \mathrm{kDa}, 31 \mathrm{kDa}$, and $20 \mathrm{kDa}$, respectively. ${ }^{1,30}$ The $c d t A B C$ genes from different species are related to each other and CDT from different genera show similarity in structure and activity. The highest sequence homology (95\%) was noted between HdCDT and the CdtABC proteins of $A$. actinomycetemcomitans, whereas homology with enteric bacteria is lower. $\mathrm{CdtB}$, which is the most conserved protein, has about $49 \%$ sequence homology with proteins from the most distantly related genera. ${ }^{3,30}$ The amino acid sequence of HdCDT was published in 1997, ${ }^{30}$ and a high-resolution crystallographic analysis of HdCDT holotoxin, reconstituted from individual recombinant subunits, has recently been published. ${ }^{31,32}$ The A. actinomycetemcomitans CDT structure has also been reported..$^{33}$

$\mathrm{CDT}$ is classified as an $\mathrm{AB}$ toxin, with an active ("A") subunit $\mathrm{CdtB}$, which directly damages DNA and a binding ("B") subunit consisting of CdtA and $\mathrm{CdtC}$, which assists in toxin attachment to target cells and promotes its internalization. 
All three components are necessary to exert potent cytotoxic activity on intact cells, as reported for HdCDT, AaCDT, and CjCDT. ${ }^{25,30,34} \mathrm{CdtB}$ shows structural features predictive of nuclease activity and has homology with mammalian DNaseI. It exerts an endonuclease activity on plasmid DNA in vitro, as shown for HdCDT, ${ }^{25} \mathrm{AaCDT},{ }^{35}$ and $\mathrm{CjCDT} .{ }^{36} \mathrm{CdtB}$ was shown to be translocated into the nucleus of mammalian cells and induces host DNA double-strand breaks (genotoxic effects), triggering the DNA repair cascade, which causes cell cycle arrest and eventually cell death. ${ }^{34,37,38}$ However, results from other studies suggest that phosphatidylinositol-3,4,5triphosphate (PIP3) phosphatase activity of CdtB may also play role in cellular toxicity. ${ }^{39-41}$ This alternative mechanism of cell intoxication can include depletion of PIP3 and suppression of protein kinase signaling pathways.$^{41}$ The binding subunit, CdtA with $\mathrm{CdtC}$, make up the cell binding to host cell membrane lipid rafts, before internalization of $\mathrm{CdtB}$ takes place, as shown for HdCDT and AaCDT. ${ }^{42,43}$ Membrane cholesterol has been involved in binding of AaCDT to the Jurkat T-cell line. ${ }^{42}$ However, recent studies on localization of AaCDT components in CHO cells indicated that CdtA is primarily responsible for anchoring and remains on the cell surface, while $\mathrm{CdtC}$ is present both on the cell surface and in the cytosol and functions as a chaperone for the CdtB. ${ }^{44}$

Alexa Fluor 488 carboxylic acid, succinimidyl ester, green-fluorescent dye (Life technologies, Invitrogen, CA) was conjugated with HdCDT (Alexa Fluor 488-HdCDT) and used to study the process of intoxication of live epithelial HeLa cells by confocal microscopy during 72 hours. The results are presented in Figure 1.

\section{CDT as a virulence factor and its role in pathogenesis of diseases}

CDT is assumed to be a virulence determinant of at least some toxin-producing bacteria. Studies indicate that CDT is a potent toxin and that the cytotoxic effects depend mainly on the cell type rather than the origin of CDT. The majority of studies on CDT toxicity are focused on in vitro models using different eukaryotic cells. CDT from different bacteria induces damage on a variety of cells. ${ }^{1,2}$ These include epithelial HeLa, HEp-2, ${ }^{45,46}$ keratinocytes, primary human fibroblasts, ${ }^{45}$ human umbilical vein endothelial cells, ${ }^{47,48}$ and various cells of hematopoietic origin. . $^{37,45,49-51}$

It was also shown that the growth of toxin-producing H. ducreyi strains resulted in destruction of epithelial HEp-2 cell monolayer, similar to the effects of purified toxin. ${ }^{52}$

Lymphocytes and myeloid cells involved in the immune response are most susceptible to CDT action, and display rapid apoptosis upon exposure, as shown for HdCDT. ${ }^{53}$ Wising et $\mathrm{al}^{45}$ demonstrated that about $90 \%$ of Jurkat T-cells or THP-1 monocytic cells undergo apoptosis within 24-48 hours after treatment with about $100 \mathrm{ng} / \mathrm{mL}$, while only $30 \%$ of HeLa or HaCaT epithelial cells or fibroblasts are intoxicated under the same conditions. The consequences of intoxication on cells involved in the immune response may contribute to the inhibition of the immune response during infection, as HdCDT has been shown to inhibit both cytokine production by antigen presenting cells (APC), to elicit T-cell activation in vitro, and to induce apoptosis. ${ }^{54}$ Thus, the extreme sensitivity of immune cells suggests that the toxin may cause immunomodulation, impairment of phagocytosis and bacterial clearance, and down regulation of downstream immune responses in vivo. ${ }^{41}$

Despite its dramatic in vitro effects, it is not clear to what extent CDT contributes to pathogenesis in infections caused by toxin-producing strains and the evidence attributing pathogenesis to HdCDT and AaCDT in human or animal disease is contradictory. ${ }^{1,2}$

The pathogenicity of $H$. ducreyi bacteria and HdCDT mutants was investigated in the low-temperature rabbit model, where bacteria injected into skin form purulent necrotic lesions, which are self-limited and differ from those described for humans. ${ }^{55}$ Destructive mutations in individual CDT subunits did not affect the ability to cause experimental lesions, which were comparable to lesions caused by the parent strain. ${ }^{56,57}$

Studies with purified HdCDT holotoxin showed that injection of $10 \mu \mathrm{g}$ into rabbit skin induced inflammation. ${ }^{58}$ Dermal injection of a nontoxin-producing variant of $H$. ducreyi together with $10 \mu \mathrm{g}$ of reconstructed HdCDT resulted in larger skin ulcers in rabbits and prolonged healing compared to lesions caused by the nontoxin-producing strain alone. ${ }^{58}$

A model of $H$. ducreyi human infection was developed, in which healthy adult volunteers were inoculated with $H$. ducreyi bacteria at multiple sites on the skin of the upper arm. ${ }^{59,60}$ In this model, papules develop within 24 hours, which either resolve spontaneously or evolve into pustules over the next 2-5 days. Volunteers remain infected until they reach the clinical endpoint, which is defined either as resolution of disease at all sites, or development of a pustule that is either painful, or with an extension of approximately $4 \mathrm{~mm}$ in diameter, or the time end-point at 14 days after inoculation. At the endpoint, all volunteers are treated with one dose of oral ciprofloxacin. Using this model, which illustrates the acute stages of $H$. ducreyi infection, it was observed that the expression of HdCDT was not required for pustule formation by $H$. ducreyi, since the isogenic 

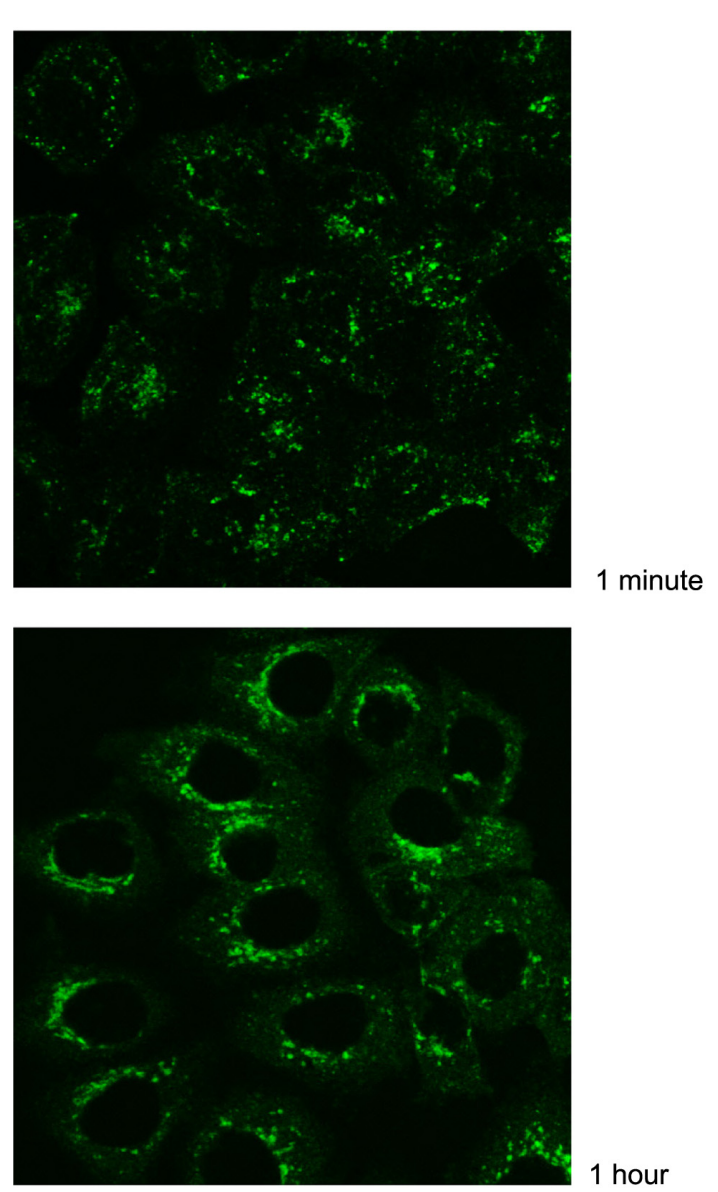

1 hour

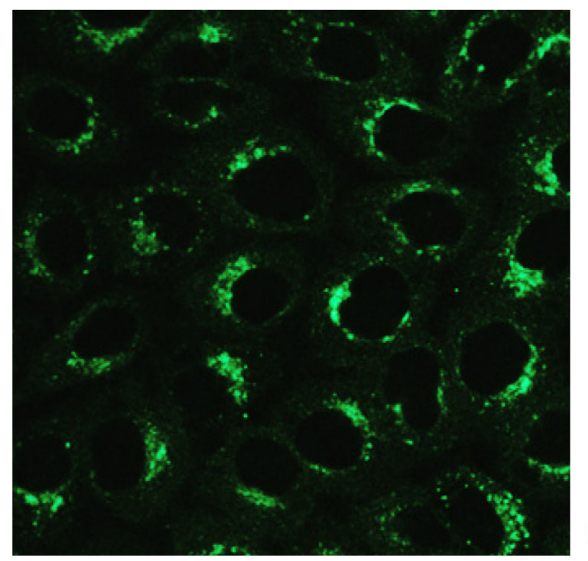

6 hours

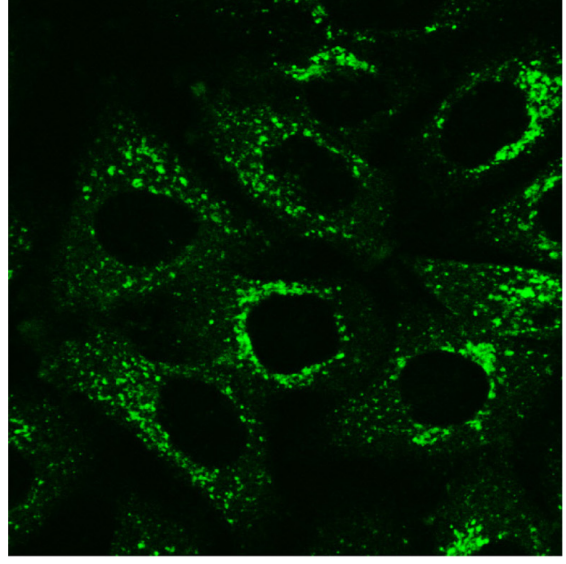

24 hours

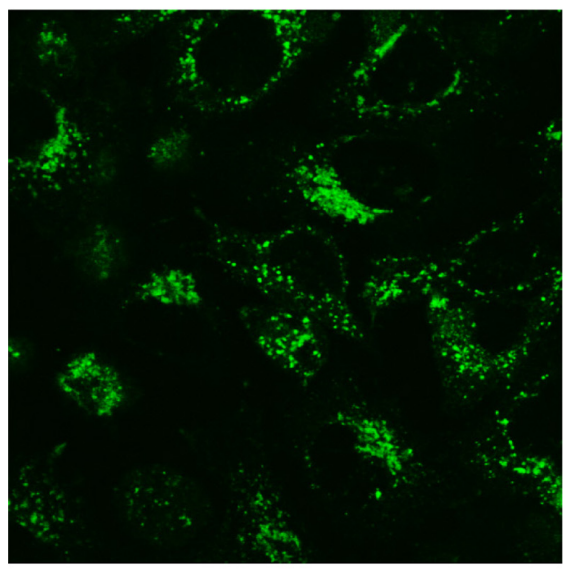

48 hours

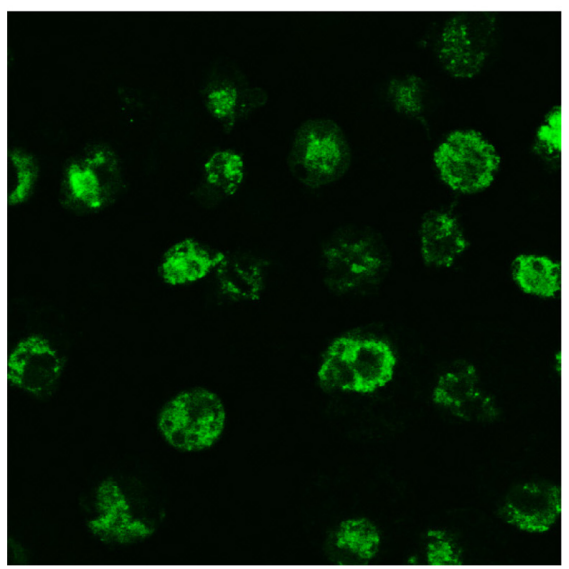

72 hours

Figure I Intoxication process of HeLa cells (ATTC CCL-2) treated with reconstructed whole cytolethal distending toxin of Haemophilus ducreyi conjugated to greenfluorescent dye (Alexa Fluor 488HdCDT) and examined by confocal microscopy during 3 days by Live Cell Imaging System (Centre for Cellular Imaging, CCI, Sahlgrenska Academy, Gothenburg University, Sweden).

Notes: The quick binding of HdCDT to cells (within I minute). HdCDT seems to be introduced to Golgi complex and to ER after about after I hour to 24 hours. Distention of cells and disintegration (cell death) is observed after 48-72 hours.

Abbreviations: HeLa cells, epithelial cell line from American Type Culture Collection (ATCC); HdCDT, Haemophilus ducreyi cytolethal distending toxin; Alexa Fluor 488-HdCDT, green-fluorescent dye, Alexa Fluor 488 carboxylic acid, succinimidyl ester conjugated to HdCDT; ER, endoplasmatic reticulum.

CdtC negative mutant produced similar lesions, ie, pustule formation, as a parental strain. ${ }^{56,61} \mathrm{CdtA}-$, $\mathrm{CdtB}-$, and $\mathrm{CdtC}-$ negative mutants, which were not toxic for cultured cells in vitro, did not differ in their capacity to develop lesions in this model of infection, compared to the parent strain and it was concluded that there is no involvement of HdCDT in the early stage of ulcer formation in skin..$^{77,59}$ The amount of toxin produced during the experimental inoculation is not known, but in later studies, transcription of genes corresponding to $\mathrm{CdtB}$ was shown to be expressed during infection in human volunteers. ${ }^{6}$ It was also demonstrated that the early immune response to $H$. ducreyi has many features of a type 
1 response, and that development of antibodies is noted late in chancroid lesions. It is possible that when polymorphonuclear leukocytes and macrophages fail to clear the organism, the type 1 response is sustained. ${ }^{59,63}$ The termination of $H$. ducreyi infection in volunteers does not allow for study of the development of typical persisting chancres in the later stage of infection. While HdCDT seems not to be involved in induction of chancroid skin lesions in the acute stage of infection, it is possible that the cytotoxic effect of CDT on certain skin cells may be responsible for the enlargement of ulcers and a typical clinical picture of persisting chancroid lesions. Moreover, hampered epithelialization, necrosis of endothelial cells and slowing of angiogenesis by CDT contribute to the slow healing of ulcers seen in untreated chancroid lesions after infection. In particular, the impact on endothelial cells and the inhibition of angiogenesis as shown in vitro is an important factor in healing. ${ }^{48,50}$ Keeping in mind that chancroid is a STI, HdCDT can play an important role in persistence of infection and in delayed healing, which, together, contribute to enhanced transmission of this STI pathogen to other hosts. ${ }^{1,64}$ The observed low activity on fibroblasts, or limited penetration to deeper tissues of CDT, may explain why chancroid ulcers remain shallow. The apoptosis induced in B and T lymphocytes by CDT suggests that the resultant immunosuppression would delay or decrease immune function, allow bacterial growth, and possibly enhance tissue damage in genital and gingival tissue seen in chancroid periodontitis, respectively. The clinical appearance and histological findings of chancroid ulcers support this hypothesis. However, there are a number of strains, which do not produce toxins, and which have been isolated from lesions. This gives a rise to the further questions: how much HdCDT is involved in chancroid, and at what stage of infection? It is possible that disease progression differs depending on whether strains are toxin producing or nontoxin producing, and on corresponding differences in the clinical appearance of ulcers. This subject requires further study. However, in many cases the early treatment with antibiotics that is the norm does not allow for such studies. In addition, it is interesting to consider that toxin-producing Corynebacterium diphtheriae strains can occasionally affect the skin (cutaneous diphtheria) with a clinical picture that is characterized by pus-filled ulcers with sharply defined borders surrounded by a zone of red and swollen skin. The ulcer, similar to chancroid, takes long time to heal (usually within 2 to 3 months) and it is likely to leave a scar. ${ }^{65}$

Studies on the topical application of $A$. actinomycetemcomitans CDT holotoxin in the rat gingival model, showed degeneration and sloughing of epithelial cells within 3 days in situ. ${ }^{66}$ The local arrest of cell proliferation of oral gingival sulci of rats was specific and not observed with mutated inactive CdtB holotoxin. These studies support the observation of Wising et al, ${ }^{58,86}$ using the rabbit model, that the CDT is cytotoxic for cells in vivo.

Studies of $A$. actinomycetemcomitans CDT activity on healthy human gingival tissue exposed to CDT ex vivo for 18-36 hours showed extensive detachment of the keratinized outer layer and distention of spinouts and basal cells in the oral epithelium. ${ }^{67}$ The connective tissue was less affected. Moreover, primary gingival cells isolated from tissues of healthy individuals exhibited cell cycle arrest when treated with the toxin ex vivo. These results, showing a direct damage of human oral epithelium and mucosa by CDT, indicate a clear role for AaCDT in the pathogenesis of periodontitis.

The involvement of CDT in the pathogenesis of gastrointestinal infections has been investigated, as well. The demonstration that oral administration of $\mathrm{CjCDT} \mathrm{CdtB}$ mutants to adult severe combined immunodeficient mice (lacking mature T and B lymphocytes) did not affect colonization by bacteria, but caused reduced invasiveness into blood, spleen, and liver tissue, which indicates a possible involvement of the toxin in the pathogenesis of enteric disease. ${ }^{68}$ However, the high doses of bacteria used ( $10^{9}$ colony-forming units) and the use of immunodeficient hosts may not be representative for natural C. jejuni infection, except possibly in immunocompromised patients. In another study, a gastroenteritis in nuclear factor $\kappa$-light-chain-enhancer of activated B cells (NF- $\kappa \mathrm{B})$-deficient mice was produced using wild-type $C$. jejuni, but not with a strain deficient in active $\mathrm{CDT} .{ }^{69} \mathrm{CjCDT}$ holotoxin was shown to induce production of the proinflammatory chemokine, CXCL8, responsible for the recruitment of neutrophils to the intestinal mucosa, ${ }^{14,70}$ which is characteristic of initial stages of infection with $C$. jejuni. However, the role of CjCDT and the importance of this inflammatory response in pathogenesis are not clear.

Another gastrointestinal pathogen, H. hepaticus, is a bacterium host adapted to mice, and constitutes a suitable model to study the role for CDT in pathogenesis of infection and disease. HhCDT has been shown to play an important role in promoting the progression of infectious hepatitis to premalignant, dysplastic lesions via activation of a proinflammatory $\mathrm{NF}-\kappa \mathrm{B}$ pathway and increased proliferation of hepatocytes, providing the first evidence that CDT may have carcinogenic potential in vivo. ${ }^{71}$ In another study in $\mathrm{IL}-10^{-/-}$mice, it was reported that CDT plays a key immunomodulatory role that allows the colonization 
and persistence of $H$. hepaticus and that this alteration of the host immune response results in the development of colitis. $^{20,21,72}$

The animal studies mentioned above suggest that CjCDT and HhCDT may cause development and increase of inflammation, persistent infection or chronic disease and retardation of healing in the gastrointestinal tract or, in case of $H$. hepaticus, liver disease in vivo. ${ }^{21}$ However, the results of a study of 30 patients with gastroenteritis, from which Campylobacter spp. were isolated and tested for CDT-encoded genes, suggested that CDT does not solely determine the severity of infection and the clinical outcome. ${ }^{73}$ CjCDT probably plays no role in direct induction of diarrhea, but can be responsible for prolonged carriage of bacteria or bacterial colonization.

As presented above, the evidence suggesting that the CDTs may be disease determinants is based mainly on studies in vitro, showing a very potent cell destruction and apoptosis in a number of different human and animal cells, and in some animal models. Direct evidence that CDT causes lesions on gut mucosa is obtained from studies with AaCDT on human mucosa ex vivo and rat mucosa in vivo.

\section{CDT as a protective antigen and the role of neutralizing antibodies}

To develop an effective vaccine, the vaccine candidate must be safe and be able to induce protection against infection, or consequences of infection. In these terms, the protective antigen must induce strong antibody or cellular responses, which inhibit or neutralize any biological effect of the toxin. Not all bacterial virulence factors are protective antigens, but many detoxified bacterial toxins act as excellent vaccines responsible for protection against, for example, diphtheria, tetanus, and pertussis. Neutralization of these secreted toxins by antibodies is the basis for protective immunity in the respective disease.

Antibodies specific to CDT components neutralize the toxic activity of HdCDT, AaCDT, and CjCDT on different cell lines in vitro, ${ }^{58,70,74,75}$ but direct experimental evidence for the protective role of antibodies to CDT in animal models or in human disease is lacking.

In the case of $H$. ducreyi infection, studies of serum samples, both from patients with chancroid and from infected volunteers, indicated that this local infection does not confer immunity against subsequent reinfection and does not induce a significant antibody response to bacterial antigens, including CDT. ${ }^{59}$ In sera from patients with chancroid, antibodies to different bacterial cell components were detected infrequently and mainly in the later stage of disease $^{76,77}$ and low levels of the toxin-neutralizing activity were detected in $66 \%$ of serum samples from culture-proven chancroid. ${ }^{78}$ Moreover, antibodies against the $\mathrm{CdtC}$ subunit correlated with disease in patients with chancroid, compared with healthy blood donors ${ }^{75,79}$ and the monoclonal antibody, M4D4, specific for the CdtC component of HdCDT, exerts a potent neutralizing activity in vitro, ${ }^{78}$ indicating that this subunit can be a major target for neutralizing antibodies against HdCDT.

Studies on induction of antibodies to HdCDT showed that experimental infection or immunization of rabbits with toxinogenic $H$. ducreyi, bacterial sonicates or purified HdCDT or HdCDT components, may result in the development of toxin-neutralizing antibodies, but titers are low. ${ }^{58,80}$ Moreover, repeated subcutaneous immunizations of mice with 5-10 $\mu \mathrm{g}$ active, purified HdCDT induced low levels of serum antiHdCDT immunoglobulin G without neutralizing capacity. ${ }^{81}$

The low levels of antibodies to HdCDT in patients with chancroid, infected volunteers and animals may have multiple causes: (i) CDT kills immune cells and thereby downregulates the immune responses; (ii) only low amounts of CDT are secreted by bacteria during growth in medium and probably the same is true for chancroid; (iii) CDT is produced locally in the lesions and quickly binds to the surface of target cells, (iv) sufficient production of toxin to evoke immune response may occur later in disease, when infection is established and bacteria multiplies.

Similar to chancroid patients the majority of patients with localized aggressive periodontitis failed to mount a significant antibody response to CDT of $A$. actinomycetemcomitans, which may explain their relative susceptibility to the disease. ${ }^{74}$ However, a response to $\mathrm{CdtC}$ was found in sera of subjects with generalized, but not of localized, aggressive periodontitis. ${ }^{82}$

It is interesting that even after diphtheria, the typical toxin-mediated disease, about $50 \%$ of patients who recover do not develop protective toxin-neutralizing antibodies, and it is therefore recommended to vaccinate convalescents. Antibodies specific to CDT have toxin-neutralizing activity and prevent cell death in vitro. In chancroid or periodontitis, antibodies may have a potential role in protection against disease by facilitating healing of the toxin-mediated lesions, thus shortening the persistence of the disease.

In patients with gastrointestinal infections caused by $C$. jejuni the development of neutralizing antibodies has been demonstrated. ${ }^{83}$ However, no neutralizing activity was detected in colonized chickens despite the expression of 
CDT in the avian gut as indicated by reverse transcriptionPCR. ${ }^{83}$

Another important issue in protection against mucosal pathogens is the presence of locally induced antibodies on mucosal surfaces. Such antibodies can be generated by the stimulation of local production or by generation of sufficient levels of serum antibodies that transude to the locus of infection, eg, the genital tract. ${ }^{84,85}$ There are no data on the levels of secreted anti-CDT antibodies on mucosal surfaces during any infection with CDT producing bacteria.

To convert CDT into a protective antigen, detoxification and treatment to increase immunogenicity has been shown to be necessary (see below). Immunization with $10 \mu \mathrm{g}$ of HdCDT toxoid evoked a strong antibody response in rabbits. Immunized rabbits with high levels of HdCDT neutralizing antibodies did not develop the typical skin inflammatory reaction seen in unimmunized animals after injection of $10 \mu \mathrm{g}$ HdCDT (Wising et al unpublished data), ${ }^{85,86}$ suggesting a protective activity of toxin neutralization in this rabbit model.

Toxin-neutralizing antibodies are protective against tetanus, diphtheria, and pertussis disease and it is well known that vaccination with toxoids alone or in combination with other bacterial antigens (pertussis vaccine) causes protection against the respective pathogens. ${ }^{87}$

In conclusion, it seems clear that antibodies to CDT neutralize toxic activity on cells in vitro, but that native CDT is a poor immunogen. More studies are clearly required to evaluate the protective role of toxin-neutralizing antibodies in animal models and in human disease.

\section{Development and evaluation of CDT toxoid as a vaccine}

The growing, albeit somewhat scant, evidence indicating that CDT is also a protective antigen, where specific antibodies neutralize the cell damage caused by toxin, justifies the attempts to develop a toxoid as a vaccine component. Such an immunogenic toxoid could be an important tool in investigation of the involvement of antibodies in protection against infection with CDT-producing bacteria.

The detoxification method commonly used for toxoid production is formaldehyde treatment ${ }^{88,89}$ and protection is achieved by parental immunization with those toxoids. The first toxoid of CDT holotoxin from $H$. ducreyi was produced by chemical detoxification with formaldehyde. ${ }^{81}$ The detoxification resulted in a toxoid with MW of approximately $80 \mathrm{kD}$, with all three components present and three doses of $10 \mu \mathrm{g}$ protein/mouse elicited toxin-neutralizing antibodies in serum at titers approximately 200 times higher than those elicited by the native toxin. ${ }^{81}$ In addition to the humoral response, high levels of antibodies were also detected in the genital tract. ${ }^{85}$ The treatment of proteins with formaldehyde involves aldehyde groups forming cross-linking by methylene bridges. The most frequent type of cross-link formed by formaldehyde is between the nitrogen atom at the end of the side-chain of lysine and the nitrogen atom of a peptide linkage, and the number of such cross-links increases with time of treatment. ${ }^{89}$ However, tyrosine, arginine, and other amino acids may be also involved. The HdCDT holotoxin possesses a total of 21 lysines: CdtA (seven residues), CdtB (two residues), and the majority are on $\mathrm{CdtC}$ (11 residues) (Figure 2). It is notable that the majority of lysines are on the $\mathrm{CdtC}$ followed by the CdtA subunit, while the tyrosine distribution on all three CDT components is more equal (five, five, and six on $\mathrm{CdtA}, \mathrm{CdtB}$, and $\mathrm{CdtC}$, respectively).

The detoxification with formaldehyde may result in destruction of the binding activity of $\mathrm{CdtA} / \mathrm{CdtC}$, and/or $\mathrm{CdtC}$ activity in the translocation of $\mathrm{CdtB}$, as well as abolishment of the enzymatic activity of CdtB. It is also possible that formaldehyde treatment retains and stabilizes the threedimensional structure of HdCDT. ${ }^{88}$ Since the CDTs from other toxin-producing pathogens are similar in composition and activity, it is expected that formaldehyde treatment could also be successfully applied to CDTs from other species. The induction of high levels of neutralizing antibodies by CDT toxoid may also facilitate investigation of the role of CDT and toxin-neutralizing antibodies in diseases caused by different microorganisms. Further developments could involve a molecular method of detoxification of $\mathrm{CdtB}$, followed by binding of CdtA and $\mathrm{CdtC}$ components; or investigation of

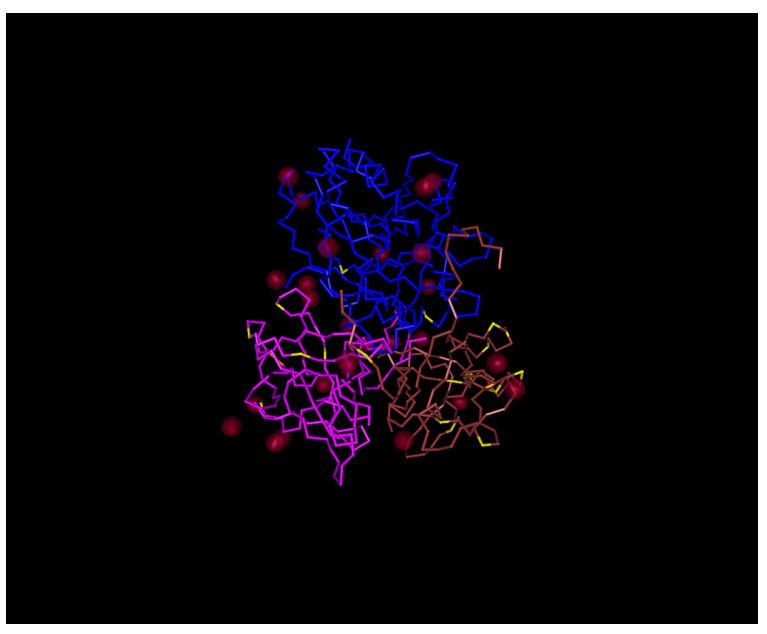

Figure 2 The crystal structure of the Haemophilus ducreyi cytolethal distending toxin.

Note: $\mathrm{CdtA}$ is marked pink, $\mathrm{CdtB}$ blue, $\mathrm{CdtC}$ brown, and lysines are yellow. 
CdtA and $\mathrm{CdtC}$ components together, or CdtC alone, as a toxoid for the induction of neutralizing antibodies. The recent studies showing a double involvement of the $\mathrm{CdtC}$ subunit in anchoring to the cell receptor and translocation of $\mathrm{CdtB}$ indicates that it may be justified to focus on this subunit. ${ }^{44}$

Recently, attempts to design a vaccine against $C$. jejuni, based on CDT subunits were published. Proteomics approaches were used to design peptides sequences which block CjCDT activity. ${ }^{90}$

\section{Conclusions}

Natural infection with CDT-producing bacteria such as $H$. ducreyi does not confer immunity to reinfection and there is very little antibody produced against CDT. As there is growing evidence for the importance of CDT activity in diseases caused by toxin-producing bacteria, it seems justified to develop a vaccine based on the CDT toxoid, given its superior immunization characteristics. However, there are still critical issues to be elucidated. The role of toxin in diseases caused by various CDT-producing pathogens probably differs between different bacteria and it is still unclear in many cases. It is still unknown if the CDT is a major virulence factor in the pathogenesis of disease. However, it is most probable that CDT produced by at least $H$. ducreyi and $A$. actinomycetemcomitans are disease determinants, since they exert antiproliferative and apoptotic activity on a number of skin/mucosa, endothelial cells and cells of the immune system, and thus may be responsible for the slow healing and chronic nature of chancroid and aggressive periodontitis. However, the attempts to elucidate the role of CDT have been limited because, for example, $H$. ducreyi and A. actinomycetemcomitans are typical human pathogens and development of animal models reflecting human chronic or persistent infection is needed. CDT does not seem to contribute directly to the induction of diarrhea in acute enteric infections caused by $C$. jejuni, but could contribute to some prolonged symptoms or colonization of some enteric pathogens.

The CDT toxins evoke a weak immune response and induce insufficient amount of antibody to neutralize the toxic effects. To ascertain the possible role of CDT as a protective antigen, detoxification and improvement of immunogenicity is necessary. The development of such toxoid vaccines may facilitate the studies of protection and immunoprophylaxis in diseases caused by CDT-producing bacteria. More studies are needed to ascertain whether the CDT toxoid could play an important role as a component of a vaccine against the CDT-producing bacterial pathogens discussed, and to define the effective route of vaccination to stimulate protective levels of systemic and mucosal antibodies.

\section{Acknowledgments/disclosure}

This work has been supported by the Royal Society of Art and Sciences in Goteborg (KVVS) and Wenner-Gren foundations. We thank Drs Paul W Bland and Leif Lindholm for critical reading of the manuscript. The authors report no conflicts of interest in this work.

\section{References}

1. Jinadasa RN, Bloom SE, Weiss RS, Duhamel GE. Cytolethal distending toxin: a conserved bacterial genotoxin that blocks cell cycle progression, leading to apoptosis of a broad range of mammalian cell lineages. Microbiology. 2011;157(Pt 7):1851-1875.

2. Smith JL, Bayles DO. The contribution of cytolethal distending toxin to bacterial pathogenesis. Crit Rev Microbiol. 2006;32(4):227-248.

3. Pickett CL, Whitehouse CA. The cytolethal distending toxin family. Trends Microbiol. 1999;7(7):292-297.

4. Trees DL, Morse SA. Chancroid and Haemophilus ducreyi: an update. Clin Microbiol Rev. 1995;8(3):357-375.

5. Lewis DA. Chancroid: clinical manifestations, diagnosis, and management. Sex Transm Infect. 2003;79(1):68-71.

6. Purven M, Lagergard T. Haemophilus ducreyi, a cytotoxin-producing bacterium. Infect Immun. 1992;60(3):1156-1162.

7. Purven M, Falsen E, Lagergard T. Cytotoxin production in 100 strains of Haemophilus ducreyi from different geographic locations. FEMS Microbiol Lett. 1995;129(2-3):221-224.

8. Ahmed HJ, Svensson LA, Cope LD, et al. Prevalence of cdtABC genes encoding cytolethal distending toxin among Haemophilus ducreyi and Actinobacillus actinomycetemcomitans strains. J Med Microbiol. 2001;50(10):860-864.

9. Sugai M, Kawamoto T, Peres SY, et al. The cell cycle-specific growthinhibitory factor produced by Actinobacillus actinomycetemcomitans is a cytolethal distending toxin. Infect Immun. 1998;66(10): 5008-5019.

10. Shenker BJ, McKay T, Datar S, Miller M, Chowhan R, Demuth D. Actinobacillus actinomycetemcomitans immunosuppressive protein is a member of the family of cytolethal distending toxins capable of causing a G2 arrest in human T cells. J Immunol. 1999;162(8): 4773-4780.

11. Fabris AS, DiRienzo JM, Wikstrom M, Mayer MP. Detection of cytolethal distending toxin activity and cdt genes in Actinobacillus actinomycetemcomitans isolates from geographically diverse populations. Oral Microbiol Immunol. 2002;17(4):231-238.

12. Yamano R, Ohara M, Nishikubo S, et al. Prevalence of cytolethal distending toxin production in periodontopathogenic bacteria. J Clin Microbiol. 2003;41(4):1391-1398.

13. Dasti JI, Tareen AM, Lugert R, Zautner AE, Gross U. Campylobacter jejuni: A brief overview on pathogenicity-associated factors and disease-mediating mechanisms. Int J Med Microbiol. 2010;300(4): 205-211.

14. Young KT, Davis LM, Dirita VJ. Campylobacter jejuni: molecular biology and pathogenesis. Nature Rev Microbiol. 2007;5(9):665-679.

15. Pickett CL, Pesci EC, Cottle DL, Russell G, Erdem AN, Zeytin H. Prevalence of cytolethal distending toxin production in Campylobacter jejuni and relatedness of Campylobacter sp. cdtB gene. Infect Immun. 1996;64(6):2070-2078.

16. Findik A, Ica T, Onuk EE, Percin D, Kevenk TO, Ciftci A. Molecular typing and cdt genes prevalence of Campylobacter jejuni isolates from various sources. Trop Anim Health Prod. 2011;43(3):711-719.

17. Martinez I, Mateo E, Churruca E, Girbau C, Alonso R, FernandezAstorga A. Detection of cdtA, cdtB, and cdtC genes in Campylobacter jejuni by multiplex PCR. Int J Med Microbiol. 2006;296(1):45-48.

18. Young VB, Knox KA, Pratt JS, et al. In vitro and in vivo characterization of Helicobacter hepaticus cytolethal distending toxin mutants. Infect Immun. 2004;72(5):2521-2527. 
19. Liyanage NP, Manthey KC, Dassanayake RP, Kuszynski CA, Oakley GG, Duhamel GE. Helicobacter hepaticus cytolethal distending toxin causes cell death in intestinal epithelial cells via mitochondrial apoptotic pathway. Helicobacter. 2010;15(2):98-107.

20. Ge Z, Feng Y, Whary MT, et al. Cytolethal distending toxin is essential for Helicobacter hepaticus colonization in outbred Swiss Webster mice. Infect Immun. 2005;73(6):3559-3567.

21. Ge Z, Schauer DB, Fox JG. In vivo virulence properties of bacterial cytolethal-distending toxin. Cell Microbiol. 2008;10(8):1599-1607.

22. Guerra L, Cortes-Bratti X, Guidi R, Frisan T. The biology of the cytolethal distending toxins. Toxins. 2011;3(3):172-190.

23. Deng K, Latimer JL, Lewis DA, Hansen EJ. Investigation of the interaction among the components of the cytolethal distending toxin of Haemophilus ducreyi. Biochem Biophys Res Commun. 2001;285(3):609-615.

24. Ueno Y, Ohara M, Kawamoto T, et al. Biogenesis of the Actinobacillus actinomycetemcomitans cytolethal distending toxin holotoxin. Infect Immun. 2006;74(6):3480-3487.

25. Frisk A, Lebens M, Johansson C, et al. The role of different protein components from the Haemophilus ducreyi cytolethal distending toxin in the generation of cell toxicity. Microb Pathog. 2001;30(6):313-324.

26. Lindmark B, Rompikuntal PK, Vaitkevicius K, et al. Outer membrane vesicle-mediated release of cytolethal distending toxin (CDT) from Campylobacter jejuni. BMC Microbiol. 2009;9:220.

27. Hassane DC, Lee RB, Pickett CL. Campylobacter jejuni cytolethal distending toxin promotes DNA repair responses in normal human cells. Infect Immun. 2003;71(1):541-545.

28. Cortes-Bratti X, Karlsson C, Lagergard T, Thelestam M, Frisan T. The Haemophilus ducreyi cytolethal distending toxin induces cell cycle arrest and apoptosis via the DNA damage checkpoint pathways. $J$ Biol Chem. 2001;276(7):5296-5302.

29. Li L, Sharipo A, Chaves-Olarte E, et al. The Haemophilus ducreyi cytolethal distending toxin activates sensors of DNA damage and repair complexes in proliferating and non-proliferating cells. Cell Microbiol. 2002;4(2):87-99.

30. Cope LD, Lumbley S, Latimer JL, Klesney-Tait J, Stevens MK, Johnson LS, et al. A diffusible cytotoxin of Haemophilus ducreyi. Proc Natl Acad Sci U S A. 1997;94(8):4056-4061.

31. Nesic D, Hsu Y, Stebbins CE. Assembly and function of a bacterial genotoxin. Nature. 2004;429(6990):429-433.

32. Nesic D, Stebbins CE. Mechanisms of assembly and cellular interactions for the bacterial genotoxin CDT. PLoS Pathog. 2005;1(3):e28

33. Yamada T, Komoto J, Saiki K, Konishi K, Takusagawa F. Variation of loop sequence alters stability of cytolethal distending toxin (CDT) crystal structure of CDT from Actinobacillus actinomycetemcomitans. Protein Sci. 2006;15(2):362-372.

34. Frisan T, Cortes-Bratti X, Thelestam M. Cytolethal distending toxins and activation of DNA damage-dependent checkpoint responses. Int $J$ Med Microbiol. 2002;291(6-7):495-499.

35. Cao L, Volgina A, Huang CM, Korostoff J, DiRienzo JM. Characterization of point mutations in the cdtA gene of the cytolethal distending toxin of Actinobacillus actinomycetemcomitans. Mol Microbiol. 2005;58(5):1303-1321.

36. Lara-Tejero M, Galan JE. A bacterial toxin that controls cell cycle progression as a deoxyribonuclease I-like protein. Science. 2000;290(5490):354-347.

37. Cortes-Bratti X, Chaves-Olarte E, Lagergard T, Thelestam M. The cytolethal distending toxin from the chancroid bacterium Haemophilus ducreyi induces cell-cycle arrest in the G2 phase. J Clin Invest. 1999;103(1):107-115.

38. Elwell CA, Dreyfus LA. DNase I homologous residues in CdtB are critical for cytolethal distending toxin-mediated cell cycle arrest. $\mathrm{Mol}$ Microbiol. 2000;37(4):952-963.

39. Boesze-Battaglia K, Brown A, Walker L, et al. Cytolethal distending toxin-induced cell cycle arrest of lymphocytes is dependent upon recognition and binding to cholesterol. J Biol Chem. 2009;284(16): 10650-10658.
40. Dlakic M. Is CdtB a nuclease or a phosphatase? Science. 2001;291 (5504):547.

41. Shenker BJ, Dlakic M, Walker LP, et al. A novel mode of action for a microbial-derived immunotoxin: the cytolethal distending toxin subunit $\mathrm{B}$ exhibits phosphatidylinositol 3,4,5-triphosphate phosphatase activity. J Immunol. 2007;178(8):5099-5108.

42. Boesze-Battaglia K, Besack D, McKay T, et al. Cholesterol-rich membrane microdomains mediate cell cycle arrest induced by Actinobacillus actinomycetemcomitans cytolethal-distending toxin. Cell Microbiol. 2006;8(5):823-836.

43. Cortes-Bratti X, Chaves-Olarte E, Lagergard T, Thelestam M. Cellular internalization of cytolethal distending toxin from Haemophilus ducreyi. Infect Immun. 2000;68(12):6903-6911.

44. Damek-Poprawa M, Jang JY, Volgina A, Korostoff J, Dirienzo JM. Localization of Aggregatibacter actinomycetemcomitans cytolethal distending toxin subunits during intoxication of live cells. Infect Immun. 2012;80(8):2761-2770.

45. Wising C, Azem J, Zetterberg M, Svensson LA, Ahlman K, Lagergard T. Induction of apoptosis/necrosis in various human cell lineages by Haemophilus ducreyi cytolethal distending toxin. Toxicon. 2005;45(6):767-776.

46. Yamamoto K, Tominaga K, Sukedai M, et al. Delivery of cytolethal distending toxin $\mathrm{B}$ induces cell cycle arrest and apoptosis in gingival squamous cell carcinoma in vitro. Eur J Oral Sci. 2004;112(5): 445-451.

47. Bielaszewska M, Sinha B, Kuczius T, Karch H. Cytolethal distending toxin from Shiga toxin-producing Escherichia coli $\mathrm{O} 157$ causes irreversible $\mathrm{G} 2 / \mathrm{M}$ arrest, inhibition of proliferation, and death of human endothelial cells. Infect Immun. 2005;73(1):552-562.

48. Svensson LA, Henning P, Lagergard T. The cytolethal distending toxin of Haemophilus ducreyi inhibits endothelial cell proliferation. Infect Immun. 2002; 70(5):2665-2669.

49. Ohara M, Hayashi T, Kusunoki Y, et al. Cytolethal distending toxin induces caspase-dependent and -independent cell death in MOLT-4 cells. Infect Immun. 2008;76(10):4783-4791.

50. Svensson LA, Tarkowski A, Thelestam M, Lagergard T. The impact of Haemophilus ducreyi cytolethal distending toxin on cells involved in immune response. Microb Pathog. 2001;30(3):157-166.

51. Shenker BJ, Hoffmaster RH, Zekavat A, Yamaguchi N, Lally ET, Demuth DR. Induction of apoptosis in human T cells by Actinobacillus actinomycetemcomitans cytolethal distending toxin is a consequence of G2 arrest of the cell cycle. J Immunol. 2001;167(1):435-441.

52. Lagergard T, Purven M, Frisk A. Evidence of Haemophilus ducreyi adherence to and cytotoxin destruction of human epithelial cells. Microb Pathog. 1993;14(6):417-431.

53. Gelfanova V, Humphreys TL, Spinola SM. Characterization of Haemophilus ducreyi-specific T-cell lines from lesions of experimentally infected human subjects. Infect Immun. 2001;69(7):4224-4231.

54. Xu T, Lundqvist A, Ahmed HJ, Eriksson K, Yang Y, Lagergard T. Interactions of Haemophilus ducreyi and purified cytolethal distending toxin with human monocyte-derived dendritic cells, macrophages and CD4+ T cells. Microb Infect. 2004;6(13):1171-1181.

55. Purcell BK, Richardson JA, Radolf JD, Hansen EJ. A temperaturedependent rabbit model for production of dermal lesions by Haemophilus ducreyi. J Infect Dis. 1991;164(2):359-367.

56. Stevens MK, Latimer JL, Lumbley SR, et al. Characterization of a Haemophilus ducreyi mutant deficient in expression of cytolethal distending toxin. Infect Immun. 1999;67(8):3900-3908.

57. Lewis DA, Stevens MK, Latimer JL, et al. Characterization of Haemophilus ducreyi cdtA, cdtB, and cdtC mutants in in vitro and in vivo systems. Infect Immun. 2001;69(9):5626-5634.

58. Wising C, Svensson LA, Ahmed HJ, et al. Toxicity and immunogenicity of purified Haemophilus ducreyi cytolethal distending toxin in a rabbit model. Microb Pathog. 2002;33(2):49-62.

59. Spinola SM, Bauer ME, Munson RS Jr. Immunopathogenesis of Haemophilus ducreyi infection (chancroid). Infect Immun. 2002;70(4): 1667-1676. 
60. Al-Tawfiq JA, Palmer KL, Chen CY, et al. Experimental infection of human volunteers with Haemophilus ducreyi does not confer protection against subsequent challenge. J Infect Dis. 1999;179(5):1283-1287.

61. Young RS, Fortney KR, Gelfanova V, et al. Expression of cytolethal distending toxin and hemolysin is not required for pustule formation by Haemophilus ducreyi in human volunteers. Infect Immun. 2001;69(3):1938-1942.

62. Throm RE, Spinola SM. Transcription of candidate virulence genes of Haemophilus ducreyi during infection of human volunteers. Infect Immun. 2001;69(3):1483-1487.

63. Spinola SM, Orazi A, Arno JN, et al. Haemophilus ducreyi elicits a cutaneous infiltrate of CD4 cells during experimental human infection. J Infect Dis. 1996;173(2):394-402.

64. Lagergard T, Bolin I, Lindholm L. On the evolution of the sexually transmitted bacteria Haemophilus ducreyi and Klebsiella granulomatis. Ann NY Acad Sci. 2011;1230:E1-E10.

65. de Benoist AC, White JM, Efstratiou A, et al. Imported cutaneous diphtheria, United Kingdom. Emerg Infect Dis. 2004;10(3):511-513.

66. Ohara M, Miyauchi M, Tsuruda K, Takata T, Sugai M. Topical application of Aggregatibacter actinomycetemcomitans cytolethal distending toxin induces cell cycle arrest in the rat gingival epithelium in vivo. J Periodontal Res. 2011;46(3):389-395.

67. Damek-Poprawa M, Haris M, Volgina A, Korostoff J, DiRienzo JM. Cytolethal distending toxin damages the oral epithelium of gingival explants. J Dent Res. 2011;90(7):874-879.

68. Purdy D, Buswell CM, Hodgson AE, McAlpine K, Henderson I, Leach SA. Characterisation of cytolethal distending toxin (CDT) mutants of Campylobacter jejuni. J Med Microbiol. 2000;49(5):473-479.

69. Fox JG, Rogers AB, Whary MT, et al. Gastroenteritis in NF-kappaBdeficient mice is produced with wild-type Campylobacter jejuni but not with $C$.jejuni lacking cytolethal distending toxin despite persistent colonization with both strains. Infect Immun. 2004;72(2):1116-1125.

70. Hickey TE, McVeigh AL, Scott DA, et al. Campylobacter jejuni cytolethal distending toxin mediates release of interleukin- 8 from intestinal epithelial cells. Infect Immun. 2000;68(12):6535-6541.

71. Ge Z, Rogers AB, Feng Y, et al. Bacterial cytolethal distending toxin promotes the development of dysplasia in a model of microbially induced hepatocarcinogenesis. Cell Microbiol. 2007;9(8):2070-2080.

72. Pratt JS, Sachen KL, Wood HD, Eaton KA, Young VB. Modulation of host immune responses by the cytolethal distending toxin of Helicobacter hepaticus. Infect Immun. 2006;74(8):4496-4504.

73. Mortensen NP, Schiellerup P, Boisen N, et al. The role of Campylobacter jejuni cytolethal distending toxin in gastroenteritis: toxin detection, antibody production, and clinical outcome. APMIS. 2011;119(9):626-634.

74. Xynogala I, Volgina A, DiRienzo JM, Korostoff J. Evaluation of the humoral immune response to the cytolethal distending toxin of Aggregatibacter actinomycetemcomitans Y4 in subjects with localized aggressive periodontitis. Oral Microbiol Immunol. 2009;24(2):116-123.

75. Lagergard T, Purven M. Neutralizing antibodies to Haemophilus ducreyi cytotoxin. Infect Immun. 1993;61(4):1589-1592.
76. Bong CT, Bauer ME, Spinola SM. Haemophilus ducreyi: clinical features, epidemiology, and prospects for disease control. Microbes Infect. 2002;4(11):1141-1148.

77. Chen CY, Mertz KJ, Spinola SM, Morse SA. Comparison of enzyme immunoassays for antibodies to Haemophilus ducreyi in a community outbreak of chancroid in the United States. J Infect Dis. 1997;175(6):1390-1395.

78. Purven M, Frisk A, Lonnroth I, Lagergard T. Purification and identification of Haemophilus ducreyi cytotoxin by use of a neutralizing monoclonal antibody. Infect Immun. 1997;65(8):3496-3499.

79. Mbwana J, Ahmed HJ, Ahlman K, et al. Specificity of antibodies directed against the cytolethal distending toxin of Haemophilus ducreyi in patients with chancroid. Microb Pathog. 2003;35(3):133-137.

80. Lagergard T. The role of Haemophilus ducreyi bacteria, cytotoxin, endotoxin and antibodies in animal models for study of chancroid. Microb Pathog. 1992;13(3):203-217.

81. Lagergard T, Lundqvist A, Wising C, Gabrielsson V, Ahlman K. Formaldehyde treatment increases the immunogenicity and decreases the toxicity of Haemophilus ducreyi cytolethal distending toxin. Vaccine. 2007;25(18):3606-3614.

82. Ando ES, De-Gennaro LA, Faveri M, Feres M, DiRienzo JM, Mayer MP. Immune response to cytolethal distending toxin of Aggregatibacter actinomycetemcomitans in periodontitis patients. J Periodontal Res. 2010;45(4):471-480.

83. Abuoun M, Manning G, Cawthraw SA, et al. Cytolethal distending toxin (CDT)-negative Campylobacter jejuni strains and anti-CDT neutralizing antibodies are induced during human infection but not during colonization in chickens. Infect Immun. 2005;73(5):3053-3062.

84. Mestecky J, Moldoveanu Z, Russell MW. Immunologic uniqueness of the genital tract: challenge for vaccine development. Am J Reprod Immunol. 2005;53(5):208-214.

85. Lundqvist A, Fernandez-Rodrigues J, Ahlman K, Lagergard T. Detoxified Haemophilus ducreyi cytolethal distending toxin and induction of toxin specific antibodies in the genital tract. Vaccine. 2010;28(36):5768-5773.

86. Wising C, Molne L, Jonsson IM, Ahlman K, Lagergard T. The cytolethal distending toxin of Haemophilus ducreyi aggravates dermal lesions in a rabbit model of chancroid. Microbes Infect. 2005;7(5-6): 867-874.

87. Pichichero ME. Booster vaccinations: can immunologic memory outpace disease pathogenesis? Pediatrics. 2009;124(6):1633-1641.

88. Rappuoli R. Toxin inactivation and antigen stabilization: two different uses of formaldehyde. Vaccine. 1994;12(7):579-581.

89. Thaysen-Andersen M, Jorgensen SB, Wilhelmsen ES, Petersen JW, Hojrup P. Investigation of the detoxification mechanism of formaldehydetreated tetanus toxin. Vaccine. 2007;25(12):2213-2227.

90. Lucchese G, Delfino AP. Developing an anti-Campylobacter jejuni vaccine. Immunopharmacology and immunotoxicology. 2012;34(3):385-390.
Vaccine: Development and Therapy

\section{Publish your work in this journal}

Vaccine: Development and Therapy is an international, peer-reviewed, open access journal that spans the spectrum of vaccine design and development through to clinical applications. The journal is characterized by the rapid reporting of application notes, reviews, original research and clinical studies in all therapeutic areas. Clinical outcomes, patient safety,

\section{Dovepress}

and programs for the development and effective, safe, and sustained use of vaccines will be a feature of the journal. The manuscript management system is completely online and includes a very quick and fair peer-review system. Visit http://www.dovepress.com/testimonials.php to read real quotes from published authors. 